\section{Child psychiatry in the 20th century}

SIR: Christopher Wardle took on a mammoth task in attempting to summarise the influences on the development of services for child and adolescent psychiatry and managed to produce a readable and informative article (Journal, July 1991, 159, 53-68)

His assertion that "Universities closed their courses for psychiatric social workers in the 1970s and recruitment ceased" is, however, factually incorrect, as the Manchester course continued at that time.

The University of Manchester has a psychiatric social work section which was founded in 1946 and since 1975 has been located in the Department of Psychiatry in the Medical School; these social workers have been much influenced by the tradition which expects teachers to practise and which requires medical schools to be responsible for the delivery of a service as an essential part of student education. The professor, 6 lecturers, 22 accredited practice teachers and 25 students are associated with four major teaching hospitals and 14 other agencies in or around Manchester. The Diploma Course in Psychiatric Social Work carries with it the Certificate of Qualification in Social Work (CQSW). The course is full time, lasts for 12 months, and combines academic teaching in the subjects of social work, psychiatry and psychology, with three supervised practice placements in approved social work agencies. Our own department in a children's teaching hospital is fortunate to have two social work practice teachers and five students.

Department of Child Psychiatry

DAVID FIRTH Booth Hall Children's Hospital Blackley

Manchester M9 2AA

Sex differences in the familial risk of schizophrenia: data from Rüdin's study

SIR: We were interested to read the study by Pulver et al (Journal, January 1992, 160, 65-71) which reported that first-degree relatives of female schizophrenic patients more often developed schizophrenia than did first-degree relatives of male schizophrenic patients. These results replicate the findings of Goldstein et al (1990) who also found a greater than twofold risk of schizophrenia in the first-degree relatives of 161 DSM-III female schizophrenic patients versus 171 male schizophrenic patients. These findings are unexpected and raise intriguing possibilities about genetic subgroups in schizophrenia (Castle \& Murray, 1990).
We are in the process of translating the classic monograph of Rüdin (1920) and decided to try and examine this issue in his data. This was the first large systematic family study of dementia praecox. Rüdin was a pupil of Kraepelin and the head of the genetic department at Kraepelin's Psychiatric Clinic in Munich. His study used surprisingly thorough methods. The diagnostic criteria of dementia praecox adopted by Rüdin were those of Kraepelin himself which were applied consistently in his own clinic and in affiliated institutions. These criteria were a characteristic disorder of will, schizophrenic thought disorder (as described by Bleuler), "intrapsychic ataxia" (as described by Stransky), relatively early age of onset, failure to make a complete and lasting recovery, and a permanent change in the premorbid personality. Cases of paraphrenia, as defined by Kraepelin, were excluded. The sample consisted of all cases of dementia praecox found among the patients admitted to three Munich hospitals over several years. Kraeplin and Rüdin knew some of these patients personally and discussed the diagnosis together. Rüdin also examined the patients' psychiatric case notes to satisfy himself that the criteria referring to the typical course of the illness were fulfilled.

In order to ascertain the family history, patients with dementia praecox were asked about their own previous medical and psychiatric history and about medical and psychiatric illnesses in their family. In addition, as many relatives as possible were contacted either in person or by post. Rüdin attempted to get independent information about the patients and their family by consulting relevant documents, such as registry office records, church registers, wills, guardianship papers, divorce papers, family trees and chronicles, and prison and police files.

Among many other factors he looked at the effect of gender in the familial transmission of dementia praecox. Table 50 in his monograph summarises his findings, dividing both probands and relatives (in his case siblings) by gender. In his main series he reports findings on the siblings of 388 males with schizophrenia and 300 females with schizophrenia. Conveniently for us he was aware of the need to agecorrect his data and presented the raw results in terms of age stratification. He divides siblings into those living and dead and into age bands of under 17 years, 17- 40 years and over $\mathbf{4 0}$ years of age.

From his data we have calculated age-corrected risk to siblings assuming an age at risk of dementia praecox being between 17 and 40 years. Cases below this age we counted as 0 , cases above as 1 and cases within this age range as 0.5 . Among the siblings of male probands, 46 were affected out of an age- 